\title{
Ovulatory cycle effects on tip earnings by lap dancers: economic evidence for human estrus? ${ }^{\text {th }}$
}

\author{
Geoffrey Miller*, Joshua M. Tybur, Brent D. Jordan \\ Department of Psychology, University of New Mexico, Albuquerque, NM 87131, USA \\ Initial receipt 16 April 2007; final revision received 26 June 2007
}

\begin{abstract}
To see whether estrus was really "lost" during human evolution (as researchers often claim), we examined ovulatory cycle effects on tip earnings by professional lap dancers working in gentlemen's clubs. Eighteen dancers recorded their menstrual periods, work shifts, and tip earnings for 60 days on a study web site. A mixed-model analysis of 296 work shifts (representing about 5300 lap dances) showed an interaction between cycle phase and hormonal contraception use. Normally cycling participants earned about US\$335 per 5-h shift during estrus, US\$260 per shift during the luteal phase, and US\$185 per shift during menstruation. By contrast, participants using contraceptive pills showed no estrous earnings peak. These results constitute the first direct economic evidence for the existence and importance of estrus in contemporary human females, in a real-world work setting. These results have clear implications for human evolution, sexuality, and economics.
\end{abstract}

(C) 2007 Elsevier Inc. All rights reserved.

Keywords: Estrus; Female sexuality; Behavioral economics; Sexual service industries; Hormonal contraception

\section{Introduction}

Estrus is a phase of increased female sexual receptivity, proceptivity, selectivity, and attractiveness. It is common across mammalian species (Lange, Hartel, \& Meyer, 2002; Lombardi, 1998), including primates (Dixson, 1998; Nelson, 2000), and seems functionally designed to obtain sires of superior genetic quality (Gangestad, Thornhill, \& GarverApgar, 2005; Thornhill, 2006). However, the conventional wisdom holds that human female estrus became uniquely "lost" or "hidden" over evolutionary time (e.g., Burt, 1992), perhaps to promote male provisioning and paternal care in long-term pair-bonded relationships (Strassmann, 1981; Turke, 1984). Contrary to this "hidden-estrus" view, recent laboratory-based studies show that women near the most fertile point of their cycle (just before ovulation) are more attractive to males, as manifest through more attractive body scent (Havlíček, Dvořáková, Bartoš, \& Flegr, 2006;

\footnotetext{
Brent D. Jordan's contribution to this project was supported by a McNair/ROP Scholars Program Fellowship.

* Corresponding author.

E-mail address: gfmiller@unm.edu (G. Miller).
}

Kuukasiarvi et al., 2004; Singh \& Bronstad, 2001), greater facial attractiveness (Roberts et al., 2004), increased softtissue body symmetry (Manning, Scutt, Whitehouse, Leinster, \& Walton, 1996), decreased waist-to-hip ratio (Kirchengast \& Gartner, 2002), and higher verbal creativity and fluency (Krug, Moelle, \& Fehm, 1999; Symonds, Gallagher, Thompson, \& Young, 2004).

While such laboratory-based findings are theoretically important, only four studies have, to our knowledge, investigated the real-world attractiveness effects of human estrus outside the laboratory.

Haselton, Mortezaie, Pillsworth, Bleske-Recheck, and Frederick (2007) photographed 30 young women-all in steady relationships and not using the pill-twice each, wearing their self-chosen clothing, once during estrus (as confirmed by hormonal assay) and once during a lowerfertility (luteal) cycle phase. Then, 42 mixed-sex raters made a forced-choice judgment ("In which photo is the person trying to look more attractive?") between the two photos of each woman (with faces obscured, leaving only body and clothing cues). They chose the woman when she was in estrus about $60 \%$ of the time-modestly but significantly above chance. This result confirmed that both male and 
female observers are perceptually sensitive to women's choice of more conspicuous and fashionable clothes during estrus. (A related real-world study by Grammer, Renninger, \& Fisher, 2004, found that mated women attending Vienna discotheques without their partners tended to dress more provocatively if they had higher estradiol levels; however, that study did not directly assess cycle phase.)

Gangestad, Thornhill, and Garver (2002) found convergent evidence that men's real-world behavior is sensitive to their female partners' estrous cues. (Note that estrous is the adjectival form of the noun estrus.) Among 31 mated women not using the pill, their sexual partners were reported as using more mate-guarding behaviors, including higher proprietariness, attentiveness, and vigilance (e.g., calling the women's cell phones at random times to see what they were doing) when the women were in estrus. This effect was especially strong when the relationship was not yet steady or exclusive-consistent with the theory that increased mate guarding of estrous women by male partners is functionally designed to deter extra-pair copulation.

Haselton and Gangestad (2006) replicated this mateguarding result among 25 normally cycling women, using a stronger repeated-measures design based on daily reports. They further found that estrous mate guarding by male partners was mediated by both men's sexual attractiveness (less-attractive men mate guarded especially more during estrus) and women's own attractiveness (less-attractive women were especially mate guarded during estrus, whereas more-attractive women were mate guarded all the time). In a subsequent study, Pillsworth and Haselton (2006) found similar results on measures of male attentiveness and expressed love.

These four studies provide some evidence that men are sensitive to estrous cues in real-world situations. However, the photo-choice results were rather modest in strength (Haselton et al., 2007), and the mate-guarding results were rather indirect measures of estrous female attractiveness (Gangestad et al., 2002; Haselton \& Gangestad, 2006; Pillsworth \& Haselton, 2006). In this article, we build upon such research by presenting the first real-world economic evidence of male sensitivity to cyclic changes in female attractiveness. Specifically, we measured the tips earned by professional lap dancers in gentlemen's clubs over a 2-month span. These dancers are highly motivated to maximize tip earnings during every shift they work, which they do by appearing more sexually attractive than the other 5 to 30 rival dancers working the same shift and by doing the "emotional labor" of "counterfeiting intimacy" with male club patrons (Barton, 2006; Beasley, 2003; Deshotels \& Forsyth, 2006; Pasko, 2002). Hence, if the hidden-estrus view is right, there should be no reliable cues of fertility available or expressed to patrons and no ovulatory cycle effects on dancer tip earnings. On the other hand, if women retain perceivable cues of estrus - if they become more attractive to male club patrons at midcycle, just before ovulation - then they might be in higher demand and earn higher tips.

\section{Background}

Because academics may be unfamiliar with the gentlemen's club subculture, some background may be helpful to understand why this is an ideal setting for investigating real-world attractiveness effects of human female estrus. The following information was gathered from interviews with local club managers and from the sociological and feminist literature on erotic dancing (Barton, 2006; Beasley, 2003; Brewster, 2003; Deshotels \& Forsyth, 2006; Enck \& Preston, 1988; Forsyth \& Deshotels, 1997; Hall, 1993; Hochschild, 1983; Lewis, 2006; Linz et al., 2000; Pasko, 2002; Ronai \& Ellis, 1989; Thompson, Harred, \& Burks, 2003).

All participants in this study worked as lap dancers in Albuquerque "gentlemen's clubs" circa November 2006 through January 2007. The clubs serve alcohol; they are fairly dark, smoky, and loud (with a DJ playing rock, rap, or pop music). Most club patrons are Anglo or Hispanic men aged 20 to 60 , ranging from semiskilled laborers to professionals; they typically start the evening by getting a stack of US\$20 bills from the club's on-site ATM and having a couple of drinks.

Dancers in these clubs perform topless but not bottomless; law requires them to wear underwear, bikinis, or similar garments to cover the pubis. Thus, menstruating dancers can wear tampons (with strings clipped short or tucked up) and change them often during heavy-flow days, without revealing any visual signs of menstruation. Dancers typically wear very little perfume, but they often have breast implants, dye their head hair, trim their pubic hair, shave their legs and underarms, and adopt a "stage name" different from their real first name. They typically do regular aerobic and resistance exercise to maintain a fit, lean body shape.

During work, each dancer performs one to three "stage dances" on an elevated central stage about every $90 \mathrm{~min}$ to advertise her presence, attractiveness, and availability for lap dances. These result in only modest tip earnings (typically US\$1-5 tips from the men seated closest to the stage, totaling only about $10 \%$ of her earnings). The rest of the dancer's time is spent walking around the club asking men if they want a "lap dance." A lap dance typically costs US $\$ 10$ per 3-min song in the main club area or US $\$ 20$ in the more private VIP lounge. Dancers typically make about two thirds of their income from the main club area and one third from the VIP area; thus, average income from each lap dance is about US\$14. Lap dances require informal "tips" rather than having explicit "prices" (to avoid police charges of illegal "solicitation"), but the economic norms of tipping are vigorously enforced by bouncers. Dancers thus maximize their earnings by providing as many lap dances as possible per shift.

In each lap dance, the male patron sits on a chair or couch, fully clothed, with his hands at his sides; he is typically not allowed to touch the dancer. The topless female dancer sits on the man's lap, either facing away from him (to display her buttocks, back, and hair) or facing him (either leaning back 
to display her breasts, and to make conversation and eye contact, or learning forward to whisper in his ear). Lap dances typically entail intense rhythmic contact between the female pelvis and the clothed male penis (Barton, 2006; Beasley, 2003).

Thus, lap dances are the most intimate form of sex work that is legal in most American cities - much more intimate than the stage dances and table dances that characterized such clubs until the late 1990s. However, most lap dance clubs strongly discourage more intimate patron-dancer contact, even in private VIP rooms, since clubs can be closed swiftly if undercover police discover that prostitution is occurring. Rather, the dancer's earnings are maximized by inducing the man to agree to further lap dances after the first 3-min song is over (Deshotels \& Forsyth, 2006; Pasko, 2002). Thus, a dancer can make up to US\$400 per hour performing for a rich, attentive patron in a VIP lounge. Club patrons will often "sample" several different dancers with one lap dance each before picking one for a more expensive multisong bout of dancing. Thus, patrons can assess the relative attractiveness of different women through intimate verbal, visual, tactile, and olfactory interaction, and those attractiveness judgments can directly influence women's tip earnings, through the number of 3-min dances that patrons request from each dancer. In these ways, estrous attractiveness effects on lap-dancer earnings in gentlemen's clubs may be stronger than in other kinds of psychology research that use photo ratings (e.g., Haselton et al., 2007) or other kinds of sex work (e.g., visual pornography, phone sex) that give fewer fertility cues across fewer modalities.

\section{Methods}

Participants were recruited through indirect e-mails (forwarded through local industry contacts), newspaper advertisements, and flyers posted near clubs. To minimize possible response biases through demand characteristics, we mentioned the ovulatory cycle only in recruitment and consent and we did not suggest that tip earnings would be examined specifically as a function of days since menstrual onset. We believe that this brief mention of possible cycle effects on tip earnings in the consent form did not bias participant responses in any particular direction.

To enter the study, each participant collected an experiment packet (containing a consent form, 14-page questionnaire, and instructions for using the online web site) from a public location on the University of New Mexico (UNM) campus. The questionnaire (with an attached subject ID number) asked about age, ethnicity, work experience, sexual experience and attitudes, menstrual cycle characteristics, contraception use, physical characteristics, education, intelligence, and personality. Signed consent forms and completed questionnaires were returned to separate boxes at UNM to maintain anonymity. Participants were also asked to use their anonymous subject ID number to $\log$ in to the web site every day for 60 days. Each day, they were to report their mood, work hours, work location, and tip earnings in US dollars and whether they had begun or ceased menstruation. Participants were offered a payment of US\$30 upon completion of the study.

A total of 18 women gave analyzable data (signed consent forms, completed questionnaires, and reported menstrual cycle data over the 60-day period); 1 additional woman completed the study but reported highly irregular menstrual activity (e.g., three different menstrual periods beginning in the same 10-day interval), rendering her unsuitable for relevant analyses. Because recruitment was through forwarded e-mails, advertisements, and flyers, it is hard to estimate the proportion of women who responded.

\section{Results}

\subsection{Participant demographics and traits}

The 14-page questionnaire completed by each participant gave extensive background information, only some of which is relevant to this study. All participants were exclusively or primarily heterosexual. All women reported regular cycles of 28-30 days; 7 were using the hormonal contraception pill, and 11 were not (and had not within the previous 3 months); none used any other form of hormonal contraception (e.g., the patch or the implant). On average, participants were 26.9 years old (S.D. $=5)$ and had 6.4 years of experience as exotic dancers (S.D. $=2.1)$. Their demographics seem representative of exotic dancers studied in previous sociological research (e.g., Barton, 2006; Deshotels \& Forsyth, 2006; Forsyth \& Deshotels, 1996; Pasko, 2002).

\subsection{Daily online reports and fertility estimates}

We asked participants to log in to our study web site daily to report whether they had started or stopped menstruating on that day and to report their tip earnings and other details of any shift they worked that day. Each participant's menstruation data were plotted on a calendar, and we recorded how many days into the cycle each participant was for each shift reported. The online data revealed that all 18 participants showed quite regular cycles ranging from 28 to 29 days in cycle length - a good match to their self-reported cycle lengths of 28-30 days.

Actuarial data (e.g., Wilcox, Dunson, Weinberg, Trussell, \& Baird, 2001) suggest that fertility is high around Days 915 of the cycle and is low around Days 1-8 (early follicular days including menstruation) and Days 16-28 (days in the luteal phase). We divided nonestrous parts of the cycle into menstrual and luteal phases because we expected that menstrual side effects (e.g., fatigue, bloating, muscle pains, irritability) might reduce women's subjective well-being and tip earnings and we wanted to be able to distinguish an estrous increase in tips from a menstrual decrease, relative to the luteal phase. Also, because fertility estimation is imperfect and fertility may be high a few days before or 




Fig. 1. Effects of ovulatory cycle (Days 1-28) on average tip earnings per shift, for normally cycling women versus women using hormonal contraception (pill users); each data point represents a 3-day average of the indicated day, the previous day, and the following day.

after the typical fertile window, we used methods similar to those of Haselton and Gangestad (2006) by conservatively estimating cycle phase. Thus, the cycle was broken up into three phases: menstrual [Days 1-5 of the cycle (Days 6-8 were dropped because participants could have been fertile and were likely not menstruating)], fertile (Days 9-15 of the cycle), and luteal [Days 18-28 of the cycle (Days 16 and 17 were dropped because participants could have been fertile)]. We then calculated an average tip-earning level for each participant in her menstrual, fertile, and luteal phases, based on all available online data in each category.

Apart from the ambiguous-fertility days dropped from our analysis, participants reported tip earnings in a total of 296 online entries, averaging 16.4 entries each (S.D. $=5.2$, range $=9-29$ ), out of the 60 days requested. Participants only logged on to the web site on about half of the days when they worked ( $27 \%$ of the 60 requested days).

The average work shift lasted $5.2 \mathrm{~h}$ (S.D. $=1.7$, range $=0$ 12), usually starting between 5 and 10 p.m. and ending between midnight and 4 a.m. Participants reported mean earnings of US\$248.73 per shift (S.D. $=$ US\$125.30). With lap dances yielding an average of about US $\$ 14$, this mean earnings level of about US $\$ 250$ reflects about 18 dances per shift. Shift length was unrelated to shift earnings $(r=-.03$, $p=.63$ ); thus, "earnings per shift," rather than "earnings per hour," was used in subsequent tip analyses. Additionally, number of hours worked per shift did not differ across cycle phase $[F(2,249)=1.19, p=.306$; menstrual mean $=5.44$, fertile mean $=5.26$, luteal mean $=5.04]$. Fig. 1 shows average tip earnings for Days 1-28 in the cycle for normally cycling women versus pill-using women.

\subsection{Effects of ovulatory cycle and contraception on tip earnings}

Our design involved multiple observations (i.e., tips per shift) for dancers, who were nested within contraception use and crossed with cycle phase; hence, we analyzed effects of cycle phase and contraception use on tip earnings using multilevel modeling (hierarchical linear modeling). Multilevel modeling is most appropriate in this context because it allows interpretable tests of cycle phase and contraception use despite multiple observations and the nonindependence of tip earnings and despite the differential number of observations between participants. Analyses were thus performed using SPSS 14.0 Mixed Models. Restricted maximum likelihood criteria were employed. Shifts (nested within individuals) were the Level 1 units of analysis, and participants were Level 2 units of analysis. Accordingly, cycle phase was a Level 1 factor and contraception use was a Level 2 factor. We report significance levels using both traditional $p$ values for null-hypothesis testing and $p_{\text {rep }}$ values (Killeen, 2005).

Main effects of cycle phase $[F(2,236)=27.46, p<.001$, $\left.p_{\text {rep }}=1.00\right]$ and contraception use $[F(1,17)=6.76, p<.05$, $\left.p_{\text {rep }}=.929\right]$ were moderated by an interaction between cycle phase and pill use $\left[F(2,236)=5.32, p<.01, p_{\text {rep }}=.964\right]$. Figs. 1 and 2 show these key results by plotting average tip earnings within each running 3-day period (Fig. 1) or each cycle phase (menstrual, fertile, or luteal; Fig. 2) for normally cycling participants versus pill-using participants.

We conducted two planned contrasts of the interaction to investigate how cycle phase moderated the difference in tip earnings between normally cycling participants and pill users. The first contrast investigated how pill use moderated differences in tip earnings between the menstrual and luteal phases. We predicted that pill-using and normally cycling participants would demonstrate a similar difference between these two phases. The second contrast investigated how pill use moderated differences in tip earnings between the fertile phase and the other two phases. We predicted that normally cycling participants would demonstrate a larger increase in the fertile phase relative to the other phases than pill-using participants.

Consistent with our predictions, the first contrast indicated that pill use does not moderate the difference between tips earned in the menstrual and luteal phases $[F(1$,

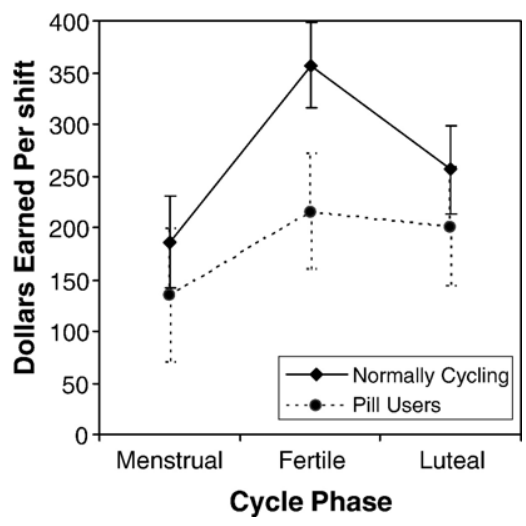

Fig. 2. Effects of ovulatory cycle phase (menstrual phase, fertile estrous phase, or luteal phase) on tip earnings per shift, for normally cycling women versus women using hormonal contraception (pill users). Error bars represent $95 \%$ confidence intervals. 
234) $=0.012, p=.911]$, with normally cycling participants demonstrating a similar increase in tip earnings from menstrual to luteal phases $(+70.45 ; 95 \%$ confidence limits from +25.68 to +115.16 ) as compared to pill-using participants $(+66.60 ; 95 \%$ confidence limits from +20.72 to +112.26 ). Also consistent with our predictions, the second contrast indicated that pill use does moderate the difference between tips earned in the fertile phase and the other two phases $\left[F(1,238)=10.52, p<.01, p_{\text {rep }}=.983\right]$, with normally cycling participants demonstrating a greater increase in tip earnings at the fertile phase relative to the other two phases $(+135.63 ; 95 \%$ confidence limits from +111.20 to +160.07$)$ than pill users $(+47.62 ; 95 \%$ confidence limits from +11.50 to +83.74$)$.

Although the sample size of individuals was small $(N=18)$, the sample size of work shifts was much larger $(N=296)$, and these work shifts reflected a sample of about 5300 lap dances (about 18 per work shift).

\section{Discussion}

We found strong ovulatory cycle effects on tip earnings, moderated by whether the participants were normally cycling. All women made less money during their menstrual periods, whether they were on the pill or not. However, the normally cycling women made much more money during estrus (about US\$354 per shift) - about US\$90 more than during the luteal phase and about US\$170 more than during the menstrual phase. Estrous women made about US\$70 per hour, luteal women made about US\$50 per hour, and menstruating women made about US $\$ 35$ per hour. By contrast, the pill users had no midcycle peak in tip earnings. As in other previous research, the pill eliminates peakfertility effects on the female body and behavior by putting the body in a state of hormonal pseudopregnancy (e.g., Gangestad, Simpson, Cousins, Garver-Apgar, \& Christensen, 2004; Gangestad et al., 2005; Macrae, Alnwick, Milne, $\&$ Schloerscheidt, 2002). This also results in pill users making only US $\$ 193$ per shift compared to normally cycling women making US\$276 per shift-a loss of more than US $\$ 80$ per shift.

This is the first direct economic evidence for the existence of estrus in contemporary human females. Under the "revealed preference" doctrine in behavioral decision theory (Camerer, 2003; Hensher, Louviere, \& Swait, 1999), real consumer spending patterns reveal human preferences more reliably than verbally stated judgments do, especially for socially stigmatized products such as pornography or sex work (Salmon \& Symons, 2001). When women and men interact intimately over the course of several minutes through conversation and body contact, women apparently either "signal" or "leak" cues of their fertility status, and these cues influence spending patterns by male consumers. These results argue against the view that human estrus evolved to be lost or hidden from males (e.g., Strassmann, 1981; Turke, 1984). Indeed, the standard argument for women's "extended sexuality" (sexual receptivity outside the fertile estrus phase) is that it evolved to help women extract material resources from males (Gangestad et al., 2005; Thornhill, 2006), and some evidence suggests that women outside estrus place a higher value on male wealth relative to other male traits (Haselton \& Miller, 2006). By this reasoning, nonestrous women in their extended sexuality phase should be better adapted to maximize tip earnings through displays of (nonfertile) sexual receptivity such as lap dancing. The fact that tip earnings peak during estrus suggests that men can detect female fertility more accurately than the "concealed ovulation" model suggested - but not so accurately that tips during the luteal and menstrual phases drop to zero (as they might if men found women generally unattractive during low-fertility parts of the cycle). As in so many coevolutionary arms races between the sexes (Arnqvist \& Rowe, 2005), this outcome is not a clear victory for either sex.

These cycle effects are notable because in previous research on gentlemen's clubs (e.g., Barton, 2006; Deshotels \& Forsyth, 2006; Pasko, 2002), summarizing thousands of hours of interviews, dancers are never reported as noticing cycle effects on tip earnings (thus making it less likely that participant expectations or demand characteristics can explain the results). Yet, dancers have rich opportunities to learn how to maximize tip earnings. Learning optimal performance in any economic game requires immediate cash feedback across many iterations of the game (Camerer, 2003), and this is exactly what lap dancers get, every few minutes, in every shift, throughout the average of 6.4 years of dance experience. For this reason, we suspect that cyclic shifts in women's attractiveness are driving our tip earnings results - rather than the well-documented shifts in sexual receptivity, proceptivity, or selectivity for good genes (e.g., Feinberg et al., 2006; Gangestad et al., 2002, 2004, 2005; Haselton \& Miller, 2006; Thornhill, 2006). Although an estrous increase in sexual receptivity and proceptivity toward clients who exhibit good-gene cues may bias dancers to approach certain men, it is unclear how this bias would lead to greater tip earnings during estrus. Indeed, it seems that the optimal strategy for obtaining tips is to focus on men who are profligate, drunk, and gullible rather than those who are intelligent, handsome, and discerning.

This study has several limitations. The sample size of participants is small $(N=18)$, although we gathered many data points per participant, which allowed us to use a statistically powerful repeated-measures design (including 296 work shifts reflecting about 5300 lap dances). Although the modest number of participants does not increase type I errors (i.e., false positives) in our statistical tests, it may reduce the generalizability of the results across populations -although it is unclear why different populations of sexually mature, normally cycling, human females would show different ovulatory cycle effects on tip earnings, if they work in the same industry.

Another limitation is that our key measures (tip earnings, menstrual cycle phases, hormonal contraception 
use) were self-reported, to maximize participant anonymity and confidentiality in this stigmatized and suspicious population (see Thompson et al., 2003). Future studies could use larger samples, could identify ovulation more precisely using the luteinizing hormone surge as measured in urine samples, and could investigate whether these effects hold in other less-stigmatized types of sex work and service and entertainment industries, in other settings and cultures.

A final limitation is that our study did not identify the precise proximal mechanisms that influence tip earnings. These might include the previously documented shifts in body scent, facial attractiveness, soft-tissue body symmetry, waist-to-hip ratio, and verbal creativity and fluency-or they might include shifts in other phenotypic cues that have not yet been studied. We can, however, exclude some possible mediators based on previous exotic dancer research. Tip earnings are unlikely to be influenced by cycle shifts in stage-dance moves, clothing, or initial conversational content because these cues just do not vary much for professional dancers (Barton, 2006; Beasley, 2003). The tip earnings pattern in Fig. 1 is similar to the pattern of estradiol levels across the cycle (with a main estrous peak and a secondary midluteal peak); hence, it is plausible that estradiol levels might mediate the tipearning effects.

Perhaps, most importantly, from an evolutionary viewpoint, further research could clarify whether women have evolved special adaptations to signal estrus through such cues-or whether the cues are "leaking" to sexually discriminating men as unselected side effects of cycle physiology. Distinguishing between estrous "signals" and "leaked cues" may be difficult in practice because estrous females (seeking extra-pair copulations with good-gene males) and extra-pair males (offering good genes) may have shared interests in female fertility signals being "conspiratorial whispers" that are accurate but inconspicuous (Pagel, 1994). In serially monogamous species such as ours, women's estrous signals may have evolved an extra degree of plausible deniability and tactical flexibility to maximize women's ability to attract high-quality extra-pair partners just before ovulation, while minimizing the primary partner's mate guarding and sexual jealousy. For these reasons, we suspect that human estrous cues are likely to be very flexible and stealthy - subtle behavioral signals that fly below the radar of conscious intention or perception, adaptively hugging the cost-benefit contours of opportunistic infidelity.

\section{Acknowledgments}

We thank Rosalind Arden, Bernadette Barton, Juliana Beasley, Steve Gangestad, Vlad Griskevicius, Martie Haselton, Catherine Salmon, Ursina Teuscher, Randy Thornhill, Rhiannon West, and several anonymous reviewers for helpful feedback on this article.

\section{References}

Arnqvist, G., \& Rowe, L. (2005). Sexual conflict. Princeton, NJ: Princeton University Press.

Barton, B. (2006). Stripped: Inside the lives of exotic dancers. New York: New York University Press.

Beasley, J. (2003). Lapdancer. New York: PowerHouse Books.

Brewster, Z. W. (2003). Behavioral and interactional patterns of strip club patrons: Tipping techniques and club attendance. Deviant Behavior, 24, 221-243.

Burt, A. (1992). Concealed ovulation and sexual signals in primates. Folia Primatologica, 58, 1-6.

Camerer, C. F. (2003). Behavioral game theory: Experiments in strategic interaction. Princeton, NJ: Princeton University Press.

Deshotels, T., \& Forsyth, C. J. (2006). Strategic flirting and the emotional tab of exotic dancing. Deviant Behavior, 27, 223-241.

Dixson, A. F. (1998). Primate sexuality: Comparative studies of the prosimians, monkeys, apes, and humans. Oxford, UK: Oxford University Press.

Enck, G. E., \& Preston, J. D. (1988). Counterfeit intimacy: A dramaturgical analysis of an erotic performance. Deviant Behavior, 9, 360-381.

Feinberg, D. R., Jones, B. C., Law Smith, M. J., Moore, F. R., DeBruine, L. M., Cornwell, R. E., et al. (2006). Menstrual cycle, trait estrogen level and masculinity preferences in the human voice. Hormones and Behavior, 49, 215-222.

Forsyth, C. J., \& Deshotels, T. H. (1996). A sociological profile of the nude dancer. International Review of Modern Sociology, 26(2), 111-120.

Forsyth, C. J., \& Deshotels, T. H. (1997). The occupational milieu of the nude dancer. Deviant Behavior, 18, 125-142.

Gangestad, S. W., Simpson, J. A., Cousins, A. J., Garver-Apgar, C. E., \& Christensen, P. N. (2004). Women's preferences for male behavioral displays shift across the menstrual cycle. Psychological Science, 15 , 203-207.

Gangestad, S. W., Thornhill, R., \& Garver, C. E. (2002). Changes in women's sexual interests and their partners' mate retention tactics across the menstrual cycle: Evidence for shifting conflicts of interest. Proceedings of the Royal Society of London Series B, 269, 975-982.

Gangestad, S. W., Thornhill, R., \& Garver-Apgar, C. E. (2005). Adaptations to ovulation. In D. M. Buss (Ed.), Handbook of evolutionary psychology (pp. 344-371). New York: Wiley.

Grammer, K., Renninger, L., \& Fisher, B. (2004). Disco clothing, female sexual motivation, and relationship status: Is she dressed to impress? Journal of Sex Research, 41, 66-74.

Hall, E. J. (1993). Smiling, deferring, and flirting: Doing gender by giving 'good service'. Work and Occupations, 20, 452-471.

Haselton, M., \& Gangestad, S. W. (2006). Conditional expression of women's desires and men's mate guarding across the ovulatory cycle. Hormones and Behavior, 49, 509-518.

Haselton, M., \& Miller, G. F. (2006). Women's fertility across the cycle increases the short-term attractiveness of creative intelligence. Human Nature, 17, 50-73.

Haselton, M. G., Mortezaie, M., Pillsworth, E. G., Bleske-Rechek, A., \& Frederick, D. A. (2007). Ovulatory shifts in human female ornamentation: Near ovulation, women dress to impress. Hormones and Behavior, $51,41-45$

Havlíček, J., Dvořáková, R., Bartoš, L., \& Flegr, J. (2006). Non-advertized does not mean concealed: Body odour changes across the human menstrual cycle. Ethology, 112, 81-90.

Hensher, D., Louviere, J., \& Swait, J. (1999). Combining sources of preference data. Journal of Econometrics, 89, 197-221.

Hochschild, A. R. (1983). The managed heart: Commercialization of human feeling. Berkeley, CA: University of California Press.

Killeen, P. (2005). An alternative to null hypothesis significance tests. Psychological Science, 16, 345-353.

Kirchengast, S., \& Gartner, M. (2002). Changes in fat distribution (WHR) and body weight across the menstrual cycle. Collegium Anthropologicum, 26, S47-S57. 
Krug, R., Moelle, M., \& Fehm, H. L. (1999). Variations across the menstrual cycle in EEG activity during thinking and mental relaxation. Journal of Psychophysiology, 13, 163-172.

Kuukasiarvi, S., Eriksson, C. J. P., Koskela, E., Mappes, T., Nissinen, K., \& Rantala, M. J. (2004). Attractiveness of women's body odors over the menstrual cycle: The role of oral contraceptives and receiver sex. Behavioral Ecology, 15, 579-584.

Lange, I. G., Hartel, A., \& Meyer, H. H. D. (2002). Evolution of oestrogen functions in vertebrates. J Steroid Biochemistry and Molecular Biology, $83,219-226$.

Lewis, J. (2006). 'I'll scratch your back if you'll scratch mine': The role of reciprocity, power, and autonomy in the strip club. Canadian Review of Sociology and Anthropology, 43(4), 297-311.

Linz, D., Bulmenthal, E., Donnerstein, E., Kunkel, D., Shafer, B. J., \& Lichtenstein, A. (2000). Testing legal assumptions regarding the effects of dancer nudity and proximity to patron on erotic expression. Law and Human Behavior, 24(5), 507-533.

Lombardi, J. (1998). Comparative vertebrate reproduction. Boston, MA: Kluwer Academic Publishers.

Macrae, C. N., Alnwick, K. A., Milne, A. B., \& Schloerscheidt, A. M. (2002). Person perception across the menstrual cycle: Hormonal influences on social-cognitive functioning. Psychological Science, 13, 532-536.

Manning, J. T., Scutt, D., Whitehouse, G. H., Leinster, S. J., \& Walton, J. M. (1996). Asymmetry and the menstrual cycle in women. Ethology and Sociobiology, 17, 129-143.

Nelson, R. J. (2000). An introduction to behavioral endocrinology (2nd ed.). Sunderland, MA: Sinauer Associates.

Pagel, M. (1994). Evolution of conspicuous estrous advertisement in OldWorld monkeys. Animal Behaviour, 47, 1333-1341.

Pasko, L. (2002). Naked power: The practice of stripping as a confidence game. Sexualities, 5, 49-66.

Pillsworth, E. G., \& Haselton, M. G. (2006). Male sexual attractiveness predicts differential ovulatory shifts in female extra-pair attraction and male mate retention. Evolution and Human Behavior, 27, 247-258.

Roberts, S. C., Havlicek, J., Flegr, J., Hruskova, M., Little, A. C., Jones, B. C., et al. (2004). Female facial attractiveness increases during the fertile phase of the menstrual cycle. Proceedings of the Royal Society of London Series B, 271(S5), S270-S272.

Ronai, C. R., \& Ellis, C. (1989). Turn-ons for money: Interactional strategies of the table dancer. Journal of Contemporary Ethnography, 18 , 271-289

Salmon, C., \& Symons, D. (2001). Warrior lovers: Erotic fiction, evolution, and female sexuality. London: Weidenfeld \& Nicholson.

Singh, D., \& Bronstad, P. M. (2001). Female body odour is a potential cue to ovulation. Proceedings of the Royal Society of London Series B, 268, 797-801.

Strassmann, B. I. (1981). Sexual selection, paternal care, and concealed ovulation in humans. Ethology and Sociobiology, 2, 31-40.

Symonds, C. S., Gallagher, P., Thompson, J. M., \& Young, A. H. (2004). Effects of the menstrual cycle on mood, neurocognitive and neuroendocrine function in healthy premenopausal women. Psychological Medicine, 34(1), 93-102.

Thompson, W. E., Harred, J. L., \& Burks, B. E. (2003). Managing the stigma of topless dancing: A decade later. Deviant Behavior, 24, 551-570.

Thornhill, R. (2006). The evolution of woman's estrus, extended sexuality and concealed ovulation and their implications for human sexuality research. In S. W. Gangestad, \& J. A. Simpson (Eds.), The evolution of mind: fundamental questions and controversies (pp. 391-396). New York: Guilford Press.

Turke, P. W. (1984). Effects of ovulatory concealment and synchrony on protohominid mating systems and parental roles. Ethology and Sociobiology, 5, 33-44.

Wilcox, A. J., Dunson, D. B., Weinberg, C. R., Trussell, J., \& Baird, D. D. (2001). Likelihood of conception with a single act of intercourse: Providing benchmark rates for assessment of post-coital contraceptives. Contraception, 63, 211-215. 